\title{
Understanding Small Business Contribution to the National Development in the Philippines
}

\author{
Kosy Timothy Nwosu ${ }^{\# 1}$, Azubuike Lucky Umeh ${ }^{* 2}$ \\ MSBA Graduate, Department of Business Administration, Saint Louis University, Baguio City, Philippines.
}

\section{The Current Climate of MSME in the Philippines}

Micro, small and medium enterprises (MSMEs) have been identified as the backbone of global economy (Bloem, 2012; Dano-Luna, Canare\& Francisco, 2018). This fact is true in a developing country such as the Philippines. The Philippine Senate Economic Planning Office (2012) noted that MSMEs are very essential to the economy as it is linked with the creation of jobs, innovation and wealth. Specifically, they are attributed with the boost of economic progress in rural areas, the provision of support services to large enterprises and the formation of new entrepreneurs and large corporations (Senate of the Philippines, 2012). As such, MSMEs are crucial partners for the realization of the fullest economic potential and growth of the Philippines. This is to say that MSMEs play a key role in the maintenance of the cooperative and competitive advantage of the Philippines in the ASEAN integration and in the global market.

On a global scale, MSMEs are defined based on three criteria which include the number of employees, total assets and annual revenue (Bloem, 2012). Different countries and organizations reconfigure these criteria and use a variety of definitions (Kushnir, 2010; Bloem, 2012). For instance, small and medium enterprises in Hongkong are those manufacturing industries with less than 100 employees and non-manufacturing enterprise with less than 50 employees (Bloem, 2012). Also, the Indian perspective defines micro, small and medium enterprises according to their investment in plant and machinery and equipment for enterprises rendering services (Bloem, 2012) In connection, an MSME is defined in the Philippines as any business enterprise engaged in industry, agri-business and/or services with an asset size (less land) of up to 100 million pesos and an employment size of less than 200 hundred employees regardless of the type of business ownership (Senate of the Philippines, 2012; RA 9501 or Magna Carta for MSMEs; SME Development Council, 2003). On a more specific note, a micro enterprise is one with an asset size of up to 3,000,000 pesos with an employment size of up to 9 employees; a small enterprise with an asset size of 3,000,001-15,000,000 pesos and an employment size from 10-99 employees; and medium enterprise with an asset of 15,000,001-100,000,000 and an employment size of 100-199 employees (RA 9501 or Magna Carta for MSMEs; SME Development Council, 2003). While the Magna Carta for MSMEs (RA 9501) provides for the operational definition of MSMEs based on assets, on the other hand, the SME Development Council, Resolution No. 1, series of 2003 defines MSMEs categories based on employment.

The enactment of a Magna Carta for MSME and other related laws and policies is reflective of the MSME climate in the Philippines. If the laws and policies are indications, the current MSME environment in the country is promising, albeit, with some issues and challenges. In addition to RA 9501 which subsequently amended RA 8289 (which also amended RA 6977), these laws include but not limited to RA 9178 or the Barangay Micro Business Enterprises Act of 2002, RA 10644 or the Go Negosyo Act of 2014 and the RA 10679 or the Youth Entrepreneurship Act of 2015 (APEC Business Advisory Council, 2016). These legislations are established to aggressively promote and support the development agenda of MSMEs (APEC Business Advisory Council, 2016). These laws also subsequently led to major changes in the institutional structure for small businesses such that new councils and programs were created and finance made available (Hampel-Milagrosa, 2014). However, the effectiveness of these policies are yet to be realized since the Philippines was reported, as of 2013, to have ranked lower compared to its East Asian neighbors across all Doing Business indicators (Hampel-Milagrosa, 2014). Therefore, as noted in the Philippine Development Plan 2017-2022, the government needs to "assess the 
implementation of, and compliance with MSME laws (i.e. Go Negosyo Act and Magna Carta for MSMEs) and determine if and where remedial legislation is needed" (NEDA, 2017; Dano-Luna, Canare\& Francisco, 2018, p. 21). Nevertheless, these policy initiatives explicitly show that the Philippine government is proactive in its support to the MSMEs as primary drivers in the economic development of the country. This make MSMEs in the Philippines conducive for upgrading and continuous improvement.

On another perspective, the current state of MSMEs development in the Philippines is moving positively but with some negative setbacks. The MSME sector dominates the total number of firms in the country with a 99.56 percent and accounts for almost 62.9 percent of the total employment, 30.3 percent of which is accounted for by microenterprises (DTI, 2017a). While the statistics looks promising in terms of employment percentage, the MSME sector has relatively low value added to the present economy with a 35.7 percent (DTI, 2017a) as compared to other Asian economies (APEC Business Advisory Council, 2016). Furthermore, an analysis of data from 2000 to 2014 reveals that the growth of MSMEs sector is modest (APEC Business Advisory Council, 2016). For example, microenterprises which account for at least 90 percent of the MSMEs have a growth rate of only 14 percent over a period of 15 years and 1 percent from 2012 to 2014 (APEC Business Advisory Council, 2016). This may be attributed to several non-financial and financial barriers such as ease of doing business and cost of starting a business (Senate of the Philippines, 2012). As such, there is a need for the country to learn how to increased MSMEs productivity (Hampel-Milagrosa, 2014) in order to achieve a sustainable growth through an improved overall business environment (Senate of the Philippines, 2012). To this end, several initiatives and efforts were launched in 2015 with the aim of linking Philippine MSMEs to the Global Value Chains (GVCs) through the digital platform (Katigbak, 2016). By tapping on the potentials of B2B e-commerce, the Philippines initiated a move towards globalizing MSMEs (Katigbak, 2016). In addition, through the ASEAN MSME Development Summit in 2017, the Philippines is consistent with its aim to advance the promotion and development of MSMEs in the ASEAN region (DTI, 2017a). In this light, the present climate of MSMEs in the Philippines

\section{Contribution to the Economy}

In the context of its role as significant partners in nation building and economic progress, MSMEs can boost the economy through its value added, employment generation and exports contribution.

First, in terms of value added, the Philippine MSMEs have 35.7 percent which is lower compared to other Asian countries such as Indonesia (53.28\%), Vietnam (39\%) and Thailand (37.8\%) (DTI, 2017a). In the 35.7 percent value added of MSME to the economy, the largest portion at 6.87 percent is contributed by the manufacturing industries, followed by the wholesale and trade industries at 6.58 percent and lastly by financial intermediation at 6 percent (DTI, 2017a). On another note, the value added percentage is divided into the contributions of small enterprises at 20.5 percent, medium enterprises at 10.3 percent and microenterprises at 4.9 percent. Overall, as of 2015, MSMEs account for about a third of the country's GDP (Mercurio, 2015). This is to say that the value added by MSMEs is not negligible. However, it is indicative of a lower productivity on the part of MSMEs as compared to large firms (Canare, Francisco \& Price, 2017). As a consequence, MSME employees may be at a disadvantage as compared with those from large businesses since productivity correlates with wages (Canare, Francisco \& Price, 2017). In turn, this also negatively affects MSMEs'"access to skilled labor since workers prefer jobs with higher productivity and higher wages (Dano-Luna, Canare\& Francisco, 2018, p. 9). The inaccessibility of skilled workers, especially the managers and supervisors, may have a negative effect on MSMEs long term performance since there is lack of strategic planners in the enterprise. This should trigger an alarm for the country to focus on the improvement of MSMEs' productivity. On a different perspective, although relatively lower, the value added percentage is still significant as it is indicative of a positive impact of MSMEs to the economy. This positive impact points to a potential larger GDP contribution with the implementation of new policies and the integration of these enterprises into the global value chains. This potential was actually eyed by the Department of Trade and Industry as it aimed to target an increased to the economic contribution of MSMEs by another 5 percent in 2016 (Mercurio, 2015).

Second, MSMEs in the Philippines have largely increased the number of employment in several industries. In comparison with large enterprises which generated 2,909, 838 jobs, MSMEs created a total of 4, 922, 251 jobs as 
DOI: $10.51386 / 25815946 /$ ijsms-v4i4p105

Volume: 4 Issue: 4

July to August 2021

https://www.ijjsmsjournal.org

of 2017 (DTI, 2017a). Thus, MSMEs contributed almost 62.9 percent of the total employment generated by all types of business establishments in 2017 (DTI, 2017). This percentage is not far from the number of other countries, both developed and developing (Canare, Francisco \& Price, 2017). In the ASEAN countries, it is noted that employment rate is between 52 to 97 percent which falls within the same percentage as that of the Philippines (Canare, Francisco \& Price, 2017). Of the 62.9 percent total jobs, 30.3 percent were generated by microenterprises, followed by small enterprises with 25.9 percent and lastly, by medium enterprises with 6.7 percent (DTI, 2017a). If rated according to industry sector, the largest portion of employment generation came from MSMEs in the Wholesale and Retail Trade and Repair of Motor Vehicles and Motorcycles at 35.5 percent, followed by the manufacturing sector, then by accommodation and food service activities, education and lastly, by financial and insurance activities (DTI, 2017a). According to region, most of the jobs are created by MSMEs in the National Capital Region (NCR) with a 32.2 percent $(1,444,769$ jobs) in the manufacturing industry. NCR is followed by CALABARZON (712, 009 jobs), then by Region 3 (495, 434 jobs), Region 7 (373, 867) and lastly by Region $6(278,366)$ (DTI, 2017a). Moreover, in 2016 MSMEs are reported to have employed nearly 5 million Filipinos in comparison with the large-sized establishments which employed 2.8 million (Gonzales, 2018). With these statistics, the MSMEs predominantly capture the employment opportunities in the Philippines (Hampel-Milagrosa, 2014). This indicates a positive relationship between the number of jobs and MSMEs. In this case, the government should also direct its attention to the pushers of business creation and renewals of MSMEs across all regions (Dano-Luna, Canare\& Francisco, 2018). On a further note, the substantial contribution of MSMEs to the employment rate of the Philippines was affirmed by the Department of Trade and Industry (Gonzales, 2018). As they provide jobs, MSMEs subsequently promote equitable and inclusive growth (Gonzales, 2018).

Lastly, MSMEs are major contributors to the national economic development of the Philippine through its exportation activities. 25 percent of the country's total exports revenue is attributed to the MSMEs (DTI, 2017a). The contribution of MSMEs in exports comes in the form of subcontracting arrangement with large businesses or as suppliers to exporting companies (DTI, 2017a). In connection, it is noted that MSMEs comprised 60 percent of the total population of exporters in the country (DTI, 2017a). This implies that the potentials of MSMEs in exports is far-reaching. However, a study reveals that majority of MSMEs do not look for new market and do not export (Dano-Luna, Canare\& Francisco, 2018). This result shows the relevance of financial access that allows for MSME to expand and increase its productivity (Dano-Luna, Canare\& Francisco, 2018). To a great extent, this result is connected with whether MSMEs are inclined or averse to export (Dano-Luna, Canare\& Francisco, 2018). Although the top reasons for the aversion of most MSME owners are associated with their entrepreneurial mindset, it is largely influenced by the business environment (Dano-Luna, Canare\& Francisco, 2018). Additionally, as the largest participant in export, MSMEs are given opportunities to link with value chain partners such as large and foreign firms. Such capacity to form linkages with value chain partners is crucial for MSME competitiveness (Dano-Luna, Canare\& Francisco, 2018). However, it is revealed that only a minor portion of the MSME has foreign firm linkages and that only 4.4 percent of them are currently engages in export (Dano-Luna, Canare\& Francisco, 2018b). As such, most MSME do not maximized this linkage opportunity (Dano-Luna, Canare\& Francisco, 2018). With this result, there is a need to look into ways to encourage MSMEs to participate in export in order to form value chain linkages with large and foreign business firm. This is in order to create and sustain the competitive advantage of MSMEs.

\section{The Need for Small Business}

Inasmuch as MSMEs are powerful engines to drive economic development and realize inclusive growth, there are issues and concerns that persistently challenge the actualization of its agenda. These challenges are related to the value added, employment creation and export contribution of MSMEs. To fully realize the potentials of MSMEs, it is imperative that stakeholders, especially the government instrumentalities, educational institutions and the private sector, coordinate and work together to help improve the contribution of MSMEs to the economy and society. This imperative has become more urgent given the backdrop of the ASEAN regional integration and global competition.

Objectively, there have been great effort to support the promotion and implementation of the development agenda of MSMEs from the government. This is through the enactment of laws and policies as well as the adoption of various programs that sought to enhance the business environment. In fact, a very good starting point for a 
tripartite collaborative movement of the government instrumentalities, educational institutions and the private sector in view of an improved MSME contribution, is the 7M strategies launched by DTI. The 7M corresponds with the terms mindset, mastery, mentoring, market, money, machines and models (Talavera, 2017). The 7M aims to empower and fully equip MSMEs in order to advanced higher into the competitive ladder while simultaneously helping sustain the entrepreneurial revolution in the Philippines (Talavera, 2017). In addition, the 7M strategies is a tactical move to address the critical challenges of MSMEs in terms of business climate, access to finance, human capital development, technology and innovation and access to market (MSMED Council, 2017).

More specifically, the strategic concepts of mindset, mastery and mentoring requires the collective effort of the government, academe and the private sector. First, the concept of mindset points to the training and orientation of entrepreneurs with the right entrepreneurial characteristics and attitude (DTI, 2017b). While this training and orientation has policy implications to government agencies, it is the task of universities to begin or reinforce this training fostered by related activities of the private sector. Next, mastery and mentoring point to the core principles of entrepreneurship that will guide and equip MSMEs with competence and know-hows in order to be successful (DTI, 2017b). In relation to these strategies, the government set up several initiatives which include the launching of Negosyo Centers to facilitate access to services for MSMEs, the SME Roving Academy as a vehicle for continuous learning, and the Mentor Me program which involves the coaching and mentoring of business practitioners to MSMEs (DTl, 2017c). These initiatives need to be monitored and empowered. Critical to the empowerment of this initiatives are the cooperation of educational institutions and the private sector. While schools and universities can offer educational programs and lessons to facilitate mastery of technical know-hows, the private sector can reinforce this mastery by coaching and mentoring from the context of practical business experience.

Still, a further look into the other strategies exposes viable opportunities for the collective effort of the government instrumentalities, educational institutions and the private sector to improve the performance of MSMEs. For one, the strategic concept of money access seeks to provide alternative sources of financing that are accessible and available at reasonable cost (MSMED Council, 2017). To this end, the government set up financing programs and services such as SME Wholesale Lending and the Pondo para saPagbabago at Pag-asenso (P3) Program and capacity building projects which include the Enterprise Enhancement Program (DTl, 2017c). To maximize the benefits of these programs, the government, in partnership with educational institutions and the private sector can increase its information dissemination about the process of availing these programs.

Another strategy looks into the need to equip MSMEs with machines that will upgrade their technology for an increased productivity and competitiveness (DTl, 2017c). On the government's end, the launching of the Shared Service Facilities project targets the advancement of MSMEs competitive edge by providing machines, equipment, tools, systems, skills and knowledge (DTl, 2017c). Increasing the awareness of MSMEs on the need to upgrade their technology through machine necessitates the participation of the academe and the private institutions. Tapping on the human and physical resources of educational and private institutions for training on the use and benefits of machines can lead to a more effective implementation of the strategic intent focused on machines.

The next strategy focused on the market access which attempts to link MSMEs with large companies and promote e-commerce platforms as a way to reach domestic and foreign buyers (DTl, 2017c). This strategy is in view of accelerating MSMEs' connectivity to markets by integrating them into the Global Value Chain. To achieve this goal, the government can incentivize big companies that will take in MSMEs as suppliers or subcontractor. Also, it is essential to set up policies that encourages MSMEs to create linkages with large and foreign companies as well as to join business organizations (Dano-Luna, Canare\& Francisco, 2018). Accordingly, "information drive on the benefits of firm linkages and memberships in business organizations can be heightened (Dano-Luna, Canare\& Francisco, 2018, p. 5). These information drives can be set up and held in partnership with schools and private institutions.

The last strategy is directed at providing business ideas or models that new entrepreneurs can adopt to start a business (DTl, 2017c). A pre-requisite to the success of this strategy is the participative efforts of the government, education and the private sectors. The government can promote and develop appropriate business models for 
MSMEs through different programs or projects. These same business models can be taught and learned in schools and in various private institutions.

In the end, the dynamic and harmonious collaboration of the government instrumentalities, educational institutions and the private sector is an imperative to the realization of the development agenda of MSMEs.

\section{Concluding Thoughts}

MSMEs are pillars tothe inclusivegrowth and economic development of the Philippines. In the Philippines, an MSME is defined as any business enterprise engaged in industry, agri-business and/or services with an asset size (less land) of up to 100 million pesos and an employment size of less than 200 hundred employees regardless of the type of business ownership (Senate of the Philippines, 2012; RA 9501 or Magna Carta for MSMEs; SME Development Council, 2003). The current climate of MSMEs in the Philippines is promising yet issues and challenges are present relative to the monitoring and implementation of policies and the overall business environment. While the Philippine government is supportive to the MSMEs, their performance is notably lagging as compared to its ASEAN neighbors. This implies that the MSMEs in the Philippines are not productive and competitive enough to secure its place in an integrated regional and global market. Policy interventions and remedial legislations are needed to redirect the path of MSMEs towards competitiveness. Else, there is a need to re-assess the implementation of policies relative to the advancement of MSMEs competitive advantage and improved performance in the country.

Policy interventions or re-assessment can consequently boost the contributions of MSMEs in terms of value-added, employment and exports. It is noted that despite the high percentage of employment created by MSMEs, it is relatively lower in term of value added. This may be attributed to several financial or non-financial constraints that persistently challenge the enterprises. Also, although the percentage of export activities from MSMEs is relatively high, there is a need to improve on the export mechanism in the Philippines. In essence, the government and stakeholders must work together to improve business capacity and the overall business environment by encouraging entrepreneurs to harness the business opportunities and untapped resources in the rural and hinterland area of the country. Most MSMEs are within the urban area in the Philippines, leaving the rural area unproductive. Umeh \& De Guzman's (2021) study has proven that rural communities are willing to accept and commit time to develop entrepreneurial innovations.

Specifically, the government instrumentalities, educational institutions and the private sector are major players in the creation of a "more globally competitive, regionally integrated, nationally resilient and productive, innovative and dynamic MSME sector" (MSMED Council, 2017). The 7M strategy of the government is a feasible starting point for a dynamic collaboration. In the strategic context of mindset, mastery, mentoring, markets, money, machine and models, the mutually inclusive tasks and responsibilities of the government, education and private institutions are present.

\section{References}

[1] APEC Business Advisory Council. (2016). Philippine MSMEs and Entrepreneurship: Pushing the Boudaries. MBS Special Publication on Innovation. 1-49.

[2] Bloem, J. (2012). Micro, Small, Medium Enterprise (MSME) Definitions. Partners Worldwide.

[3] Canare, T, Franciso, J.P. \& Price, N.A. 2017. An Empirical Analysis of SME and Large Business Linkages: Evidence from the Philippines. AIM Rizalino S. Navarro Policy Center for Competitiveness, Working Paper Series 2017-007.

[4] Dano-Luna, M., Canare, T., \& Francisco, J.P. 2018b. Drivers of SME Competitiveness: Results of the 2018 SME Survey. AIM Rizalino S. Navarro Policy Center for Competitiveness, Working Paper Series 2018-003.

[5] Department of Trade and Industry. (2017a). MSME Statistics 2017.

[6]

(2017b). MSME Development in the Philippines. Bureau of Small and Medium Enterprise Development. 


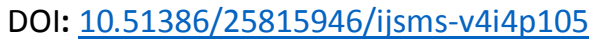

Volume: 4 Issue: 4

July to August 2021

https://www.ijjsmsjournal.org

[7] (2017c). PH advocates development of MSMEs

[8] Gonzales, A.L. (2018, March 22). DTI: MSMEs important for PH economic growth. The Manila Times.

[9] Gonzales, J. (2018, June 30). How many Filipinos are employed by the MSMEs? Business World.

[10] Government of the Philippines. Republic Act 9501. Magna Carta for Micro, Small and Medium Enterprises (MSMEs).

[11] Hampel-Milagrosa, A. (2014). Micro and small enterprise upgrading in the Philippines: The role of the entrepreneur, enterprise, networks and business environments. German Development Institute: Bonn.

[12] Katigbak, J.J. 2016. Globalizing MSMEs via B2B Commerce Considerations for the Philippines. Center for International Relations and Strategic Studies Commentaries. 3 (11), 1-3.

[13] Kushnir, K. (2010). Companion Note for the MSME Country Indicators. World Bank.

[14] Mercurio, R. (2015, November 24). SMEs eyed to hike GDP contribution. The Philippine Star.

[15] MSMED Council. (2017). Micro, Small and Medium Enterprise Development Plan 2017-2022.

[16] Philippine Statistics Authority. (2014). MSME Macro Statistics 2014.

[17] Senate of the Philippines. (2012). the MSME Sector at a Glance. Senate Economic Planning Office.

[18] Talavera, C. (2017, October 4). DTI lays out 7M strategy to develop MSMEs. The Philippine Star.

[19] Umeh, A. L., \& De Guzman, L., I. (2021). Diffusing Entrepreneurial Innovation and Tourism: An Empirical Evidence of Permaculture. International Journal of Business Studies Vol. 5 No. 2, pp.118-137. https://doi.org/10.32924/ijbs.v5i2.197 